\title{
Stanford type B aortic dissection is more frequently associated with coronary artery atherosclerosis than type $\mathrm{A}$
}

\author{
Naoki Hashiyama', Motohiko Goda², Keiji Uchida ${ }^{2}$, Yukihisa Isomatsu², Shinichi Suzuki², Makoto Mo',
} Takahiro Nishida ${ }^{4}$ and Munetaka Masuda ${ }^{2,3}$

\begin{abstract}
Background: The relationship between aortic dissection and coronary artery disease is not clear. The purpose of this study was to clarify the difference in the rate of coronary artery atherosclerosis between Stanford type A and type $B$ aortic dissection by reviewing our institutional database.

Methods: One hundred and forty-five patients (78 males, 67 females; mean age: $60 \pm 12$ years) admitted to our hospital with acute aortic dissection who underwent coronary angiography during hospitalization from 2000 through 2002 were enrolled in this study. The background characteristics, coronary risk factors, and coronary angiography findings (number of significant stenoses, stenoses according to Bogaty standards, extent index) of patients were compared between type A (Group A; $n=71$ ) and type B dissection (Group B; $N=74$ ).

Results: Significantly more patients had prior histories of complications from ischemic heart disease in Group $B$ than in Group A $(P=0.04)$, with no significant differences in comparison to other risk factors observed except for hypertension. Significantly $(p=0.005)$ more stenoses were observed in Group B $(1.54 \pm 0.04)$ than in Group A $(0.38 \pm 0.1)$. A significantly higher $(P<0.05)$ index score indicating the severity of coronary atherosclerosis was observed in Group B (1.49 \pm 0.09$)$ than in Group A (0.72 \pm 0.07$)$.

Conclusions: Stanford type B acute aortic dissection was significantly more frequently associated with coronary artery atherosclerosis than type A.
\end{abstract}

Keywords: Acute aortic dissection, Stanford classification, Coronary artery, Athroscrelosis, Coronary angiography

\section{Background}

While the survival rate of surgical patients with acute aortic dissection (AAD) has been improving recently, it remains over $10 \%$ in Asian and Western developed countries [1-3]. We previously reported that the ST-T abnormality on admission electrocardiograms in AAD patients was a significant risk factor of in-hospital mortality $[4,5]$. The prevalence of coronary artery disease due to not only dissection involved but also atherosclerotic stenosis must therefore be taken into account in the treatment of AAD. However, the relationship between coronary artery diseases and AAD remains unclear.
Recently, coronary artery computed tomography $(\mathrm{CT})$ has been used widely because of its convenience and low invasiveness [6]. However, an angiographic evaluation of coronary arteries is still clinically important and reliable because coronary CT cannot evaluate coronary lesions adequately in cases of severe coronary artery calcification.

The purpose of this study was to clarify the relationship between coronary artery disease and AAD in accordance with Stanford type A and B based on coronary angiogrphy (CAG) by reviewing our local AAD database during a time when we routinely performed CAG in AAD patients.

\footnotetext{
* Correspondence: gogomotto@gmail.com

${ }^{2}$ Department of Cardiovascular Surgery, Yokohama City University Hospital,

Fukuura 3-9, Kanazawaku, Yokohama 236-0004, Japan

Full list of author information is available at the end of the article
}

(c) The Author(s). 2018 Open Access This article is distributed under the terms of the Creative Commons Attribution 4.0 International License (http://creativecommons.org/licenses/by/4.0/), which permits unrestricted use, distribution, and reproduction in any medium, provided you give appropriate credit to the original author(s) and the source, provide a link to the Creative Commons license, and indicate if changes were made. The Creative Commons Public Domain Dedication waiver (http://creativecommons.org/publicdomain/zero/1.0/) applies to the data made available in this article, unless otherwise stated. 


\section{Methods}

\section{Study design and patient population}

This retrospective cohort study was performed at a single Japanese center in human subjects and was reviewed and approved by the Institutional Review Board at Yokohama City University Medical Center. Informed consent for this study was waived because no individual patients were identified.

We identified 145 patients (78 males, 67 females; mean age: $60 \pm 12$ years) who had undergone coronary angiography, among 221 patients hospitalized at our center from January 2000 to December 2002, when we routinely performed CAG in AAD patients. Seventy-six patients in whom CAG was not performed were excluded (49 with type $\mathrm{A}$ and 27 with type $\mathrm{B})$. Patients presenting with traumatic aortic dissection or Marfan syndrome were also excluded. The remaining 145 patients who underwent coronary angiography were included in this study and divided into 2 groups based on the type of AAD: Stanford type A acute aortic dissection $(\mathrm{A} ; n=71)$ and Stanford type B (Group B; $n=74$ ) aortic dissection.

\section{Clinical evaluation}

The baseline clinical data of the enrolled patients, including the patient demographics, medical history, clinical findings at presentation, imaging study results and preoperative complications, were collected by a retrospective chart review. Type A aortic dissection was defined as observing an intimal flap separating 2 lumina in the ascending aorta with a presentation within 14 days of its onset [7].

\section{Angiographic analyses of the coronary artery (Fig. 1)}

We performed CAG within three weeks after emergency aortic surgery in Group A or admission in Group B.

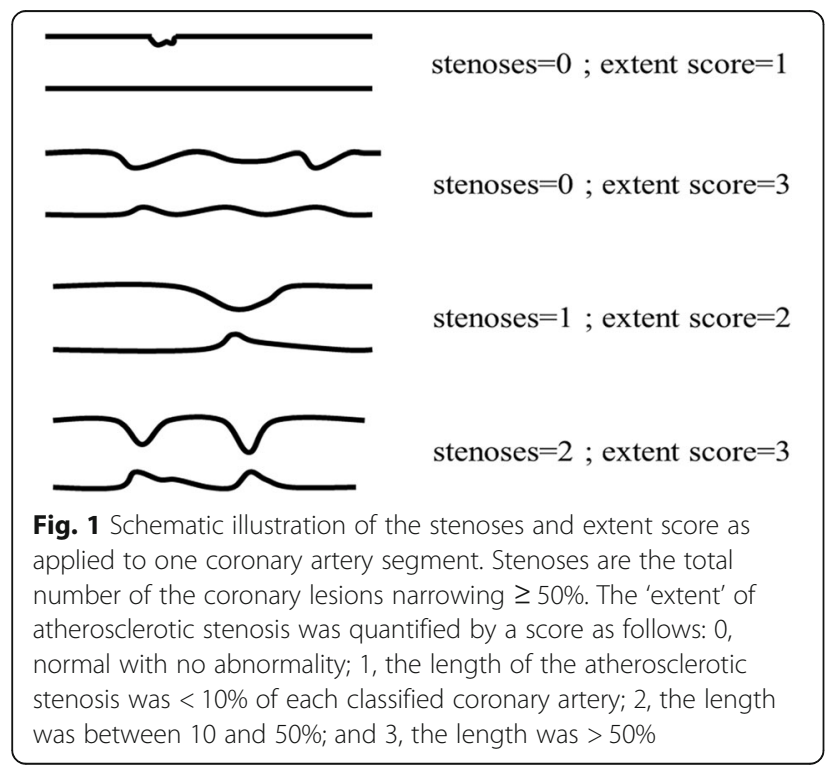

The angiograms were comprehensively analyzed based on the descriptive concepts developed and described by Bogaty et al.: severity, stenosis and extent [8]. In brief, 'severity' was defined as the number of major epicardial vessels with stenosis $\geq 75 \%$. A left main trunk with stenosis $\geq 50 \%$ was defined as 2 vessels. 'Stenoses' were defined as the total number of stenosis $\geq 50 \%$. The 'extent' of atherosclerotic stenosis was quantified by a score as follows: 0 , normal: 1 , the length of the atherosclerotic stenosis was $\leq 10 \%$ of each classified coronary artery: 2, the length was between 10 and 50\%: and 3, the length was $\geq 50 \%$. The extent index was the extent score divided by the number of coronary arteries with a proper antegrade flow, allowing a range from 0 to 3 (extent score 0-45 divide by the classical 15 segments of the coronary artery).

\section{Statistical analyses}

All statistical analyses were performed using the IBM SPSS statics software program, ver. 20 (IBM Corporation, Armonk, NY, USA). All continuous variables are presented as the means \pm standard error. Fisher's exact test and Student's $t$-tests were used for the univariate analyses. Categorical variables are expressed as absolute numbers or percentages and were compared using chi-squared testing. $P<0.05$ was considered to be significant.

\section{Results}

Patient's characteristics and coronary risk factors

All variables are listed in Tables 1 and 2 . The proportion of women was significantly higher in Group A than in Group B (56.3\% vs. 36.5\%; $p=0.02)$. Ischemic heart disease ( $3 \%$ vs $12 \% ; P=0.04)$ and arterial hypertension (55\% vs. $80 \% ; p=0.003)$ were observed significantly more frequently in Group B than in Group A. No significant differences were observed between the two groups in the age, height, body weight or other coronary

Table 1 Clinical characteristics of the patients

\begin{tabular}{llll}
\hline Variables & $\begin{array}{l}\text { Group A } \\
(n=71)\end{array}$ & $\begin{array}{l}\text { Group B } \\
(n=74)\end{array}$ & $p$ value \\
\hline Gender (Men/Women) & $31 / 40$ & $47 / 27$ & 0.02 \\
Age (years) & $60 \pm 1.4$ & $60 \pm 1.3$ & 0.725 \\
Height (cm) & $160 \pm 1.2$ & $163 \pm 0.9$ & 0.052 \\
Weight & $62 \pm 1.7$ & $65 \pm 2$ & 0.21 \\
History of coronary artery disease & $2(3 \%)$ & $9(12 \%)$ & 0.042 \\
$\quad$ Angina pectoris & 1 & 6 & \\
$\quad$ Myocardial infarction & 0 & 1 & \\
Previous coronary surgery & 1 & 2 & \\
\hline
\end{tabular}

A: Stanford type A dissection; B: Stanford type B dissection Continuous variables are expressed as the mean \pm standard error and categorical variables as the number (\%) or as indicated 
Table 2 Coronary risk factors

\begin{tabular}{llll}
\hline Variables & $\begin{array}{l}\text { Group A } \\
(n=71)\end{array}$ & $\begin{array}{l}\text { Group B } \\
(n=74)\end{array}$ & $p$ value \\
\hline Hypertension & $39(55 \%)$ & $59(80 \%)$ & 0.003 \\
Hyperlipidemia & $11(15 \%)$ & $15(20 \%)$ & 0.594 \\
Diabetes Mellitus & $5(7 \%)$ & $11(15 \%)$ & 0.216 \\
Smoking habit & $30(42 \%)$ & $37(50 \%)$ & 0.406 \\
Family history & $28(39 \%)$ & $30(41 \%)$ & 0.865 \\
\hline
\end{tabular}

A: Stanford type A dissection; B: Stanford type B dissection

Continuous variables are expressed as the mean \pm standard error and categorical variables as the number (\%) or as indicated

risk factors, including hyperlipidemia, diabetes mellitus, smoking habit and a family history of coronary disease.

\section{Coronary artery analyses}

\section{- Severity:}

Only 3 patients in Group A (4.2\%) had a single-vessel coronary disease detected by CAG, while 16 patients in Group B (21.6\%) had significant coronary disease, including 8 patients with single-vessel disease, 4 with double-vessel disease and 4 with triple-vessel disease. $(p=0.04$ : Fig. 2).

\section{- Stenoses}

Significantly fewer $(p=0.005)$ total numbers of stenoses ( $\geq 50 \%)$ were observed in Group A (26 lesions, 0.38 lesions per patient) than in Group B (114 lesions, 1.54 lesions per patient: Fig. 3).

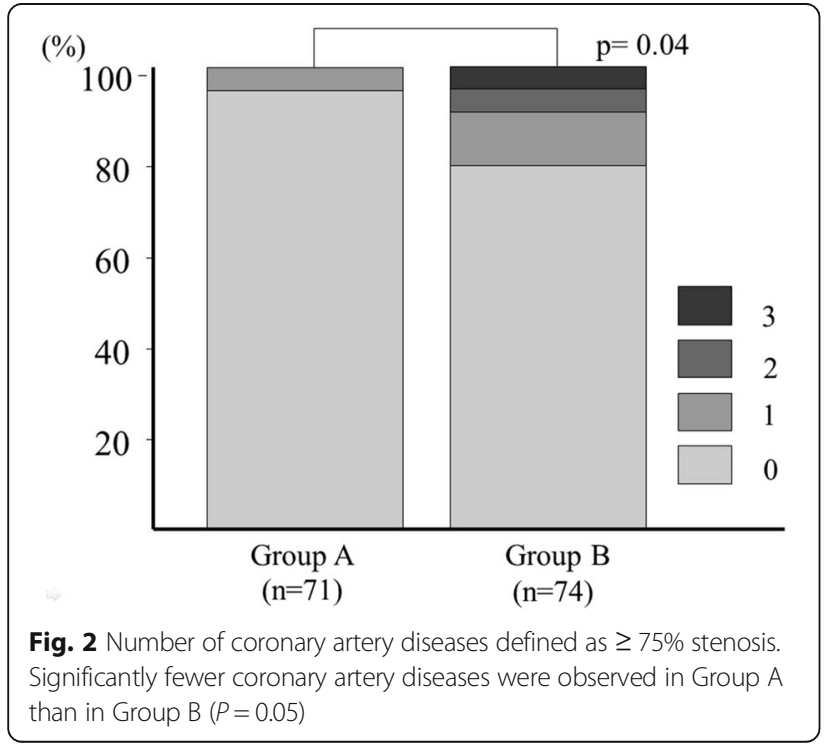

(No.ofstenoses)

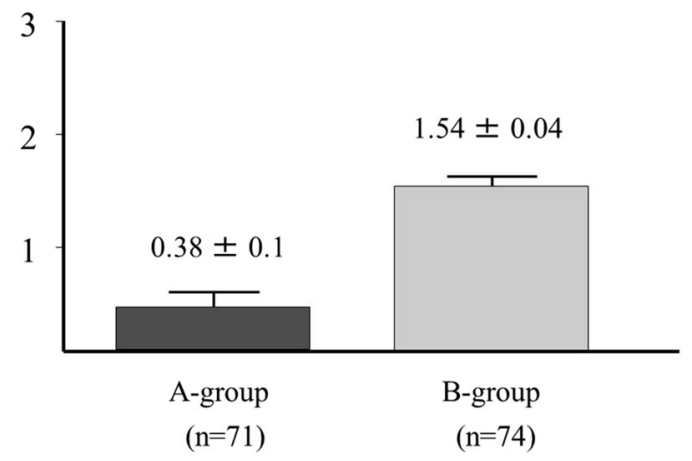

Fig. 3 Number of significant stenoses ( $\geq 50 \%)$. Significantly fewer ( $p=0.005$ ) total numbers of stenoses ( $\geq 50 \%$ ) were observed in Group A (26 lesions, 0.38 lesions per patient) than in Group B (114 lesions, 1.54 lesions per patient)

\section{- Extent}

There was also a significant difference in the extent index, representing the longitudinal extension of atherosclerotic stenosis between Group A (0.72) and Group B (1.49, $p=0.005$ : Fig. 4).

\section{Discussion}

AAD naturally has an extremely poor prognosis, and it has been noted that many cases prove fatal shortly after the onset with emergency operation normally required to rescue patients suffering from type A aortic dissection [1-3]. Exclusion of the entry by replacing the dissected ascending aorta and/or aortic arch to the artificial graft is the standard technique for Stanford A dissection; however, surgeons generally do not recognize asymptomatic coronary artery disease without ST-T changes in the electrocardiogram because CAG or coronary CT are not routinely performed before emergent operation. Therefore, treating AAD still carries a potential risk for

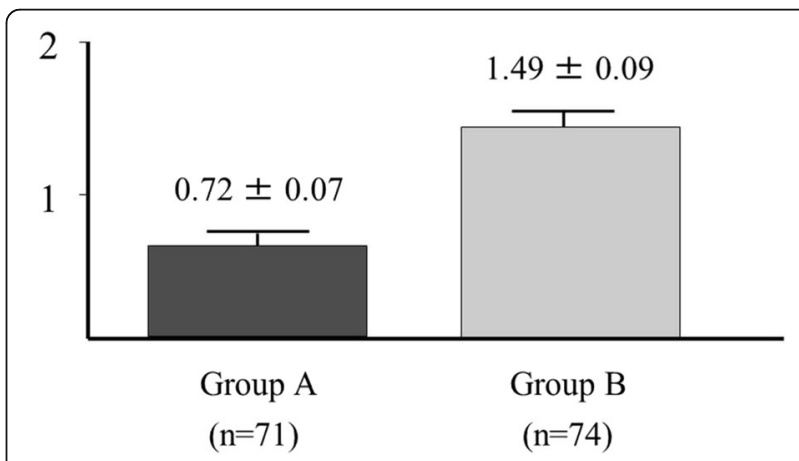

Fig. 4 Extent of coronary lesions. There was also a significant difference in the extent index, representing the longitudinal extension of atherosclerotic stenosis between Group A (0.72) and Group B $(1.49, p=0.005)$ 
severe coronary stenosis leading to perioperative myocardial infarction $[9,10]$.

Only a few reports exist concerning cases of AAD complicated by organic coronary artery atherosclerosis, but in general, complications due to coronary atherosclerosis are still believed to occur with a low frequency [11-13]. Furthermore, there has never been a report describing the relationship between significant atherosclerotic coronary artery stenosis and the Stanford classification. To prevent perioperative myocardial infarction, it is desirable to confirm the presence or absence of significant coronary stenosis during treatment for AAD, especially before emergent operation for type A dissection. Because it is not always possible to examine coronary arteries before emergent operation, it is important to clarify the underlying relationship between atherosclerotic coronary artery stenosis and AAD. Therefore, we examined AAD cases associated with coronary artery atherosclerosis based on coronary angiographical analyses to clarify the incidence of atherosclerotic coronary artery stenosis in these patients.

The present results showed that the number of significant stenoses, overall number of stenoses and extent index indicating the severity of coronary lesions were significantly higher in Group B than in Group A and only 3 of the 71 patients in Group A (4.2\%) had single-vessel coronary disease with no patients undergoing CABG in this group. These data suggest that it is not always neccessary to perform a precise coronary artery examination befroe emergent operation for type A dissection, especially in cases with no significant ST-T changes before surgery. In contrast, 16 of the 74 patients in Group B (22\%) had coronary artery disease. Thus, in cases of type B dissection, CAG is required to rule out coronary artery disease after the medical treatment of type B dissection.

Why significant differences in the coronary artery lesions were observed between type A and B dissection in our current study in unclear. Some studies have reported that atherosclerosis does not significantly contribute to AAD development [14-16]. However, recent reports from IRAD investigators $[17,18]$ have shown that the prevalence of coexisting atherosclerosis, aortic aneurysm and even hypertension was significantly higher in type B dissection than in type A dissection, which certainly supports the results of this current study. Indeed, Group B had more atherosclerotic risk factors than Group A in the present study, including proportions of male gender, hypertension and a history of coronary disease. Based on these present and previous findings, we hypothesize that the development of type A dissection is less attributable to atherosclerosis than type B dissection, leading to fewer atherosclerotic coronary lesions.

In addition, several striking reports have described a negative association between atherosclerosis and type A aortic dissection [19], ascending aortic aneurysm [20] and thoracic aortic aneurysm [21]. Although the mechanisms underlying these observations were unclear, those authors hypothesized that the same genetic mutations were responsible for (1) the progressive loss and destruction of elastic fibers or smooth muscle cells in the ascending aortic media leading to aortic dissection and (2) a protective effect against atherosclerosis.

\section{Conclusions}

Stanford type B acute aortic dissection was significantly more frequently associated with coronary artery atherosclerosis than type A. These data suggest that a precise coronary examination is not required before emergent operation for type A dissection, while CAG or coronary $\mathrm{CT}$ is required to rule out coronary artery disease in patients with type B dissection.

\section{Study limitation}

This study was based on old data derived from a single center. Furthermore, the small number of subjects did not give the study adequate power to reach robust conclusions.

\section{Abbreviations \\ AAD: Acute aortic dissection; CAG: Coronary angiography; CT: Computed tomography}

\section{Availability of data and materials \\ The dataset analyzed during the current study are available from the corresponding author on reasonable request.}

\section{Authors' contributions}

Concept/design: $\mathrm{NH}$, Data collection: $\mathrm{NH}, \mathrm{MG}, \mathrm{KU}, \mathrm{SS}$, Data analysis/interpretation: $\mathrm{NH}$, Drafting article: $\mathrm{NH}, \mathrm{MG}, \mathrm{TN}$, Critical revision of the article: $\mathrm{MG}, \mathrm{KU}, \mathrm{YI}, \mathrm{SS}, \mathrm{MMo}$, MMasuda, Approval of the article: MMasuda. NH and MG contributed equally to this work. All authors read and approved the final manuscript.

\section{Ethics approval and consent to participate}

This retrospective cohort study was performed at a single Japanese center in human subjects and was reviewed and approved by the Institutional Review Board at Yokohama City University Medical Center. Informed consent for this study was waived because no individual patients were identified.

Consent for publications

Not applicable.

\section{Competing interests}

The authors declare that they have no competing interests.

\section{Publisher's Note}

Springer Nature remains neutral with regard to jurisdictional claims in published maps and institutional affiliations.

\section{Author details}

${ }^{1}$ Department of Cardiovascular Surgery, Yokohama Minami-kyosai Hospital, Mutsuurahigashi 1-21-1, Kanazawa-ku, Yokohama 236-0037, Japan.

${ }^{2}$ Department of Cardiovascular Surgery, Yokohama City University Hospital, Fukuura 3-9, Kanazawaku, Yokohama 236-0004, Japan. ${ }^{3}$ Cardiovascular Center, Yokohama City University Medical Center, Yokohama, Japan.

${ }^{4}$ Department of Cardiovascular Surgery, Yokohama Citizen's Municipal Hospital, Yokohama, Japan. 
Received: 14 March 2018 Accepted: 19 June 2018

Published online: 27 June 2018

\section{References}

1. Committee for scientific affairs, the Japanese associasion for thoracic surgery, Masuda M, Okumura M, Doki Y, Endo S, Hirata Y et al. Thoracic and cardiovascular surgery in Japan during 2014: Annual report by The Japanese Association for Thoracic Surgery. Gen Thorac Carduovasc Surg. 2016;64:665-97.

2. Goda M, Imoto K, Suzuki S, Uchida K, Yanagi H, Yasuda S, et al. Risk analysis for hospital mortality in patients with acute type a aortic dissection. Ann Thorac Surg. 2010;90:1246-50.

3. Raghupathy A, Nienaber CA, Harris KM, Myrmel T, Fattori R, Sechtem U, et al. Geographic differences in clinical presentation, treatment, and outcome in acute type a aortic dissection (from the international registry of acute aortic dissection). Am J Cardiol. 2008:102:1562-6.

4. Kosuge M, Uchida K, Imoto K, Hashiyama N, Ebina T, Hibi K, et al. Frequency and implication of ST-T abnormalities on hospital admission electrocardiogram in patients with type a acute aortic dissection. Am J Cardiol. 2013;112:424-9.

5. Kosuge M, Kimura K, Uchida K, Masuda M, Tamura K. Clinical implication of electrocardiogram for patients with type A acute aortic dissection. Circ J. 2017; https://doi.org/10.1253/circ.CJ-17-0309.

6. Raman SV, Zareba KM. Coronary artery disease testing: past, present and future. JACC Cardiovascular imaging. 2017; https:/doi.org/10.1016/j.jcmg.2016.11.023.

7. Evangelista A, Mukherjee D, Mehta $\mathrm{RH}$, et al. Acute intramural hematoma of the aorta: a mystery in evolusion. Circulation. 2005:111:1063-70.

8. Bogaty P, Brecker SJ, White SE, Stevenson RN, El-Tamimi H, Balcon R, et al. Comparison of coronary angiographic findings in acute and chronic first presentation of ischemic heart disease. Circulation. 1993;87:1938-46.

9. Guenther SPW, Peterss S, Reichelt A, Born F, Fischer M, Pichlmaier M, et al. Diagnosis of coronary affection in patients with AADA and treatment of postcardiotomy myocardial failure using extracorporeal life support (ECLS). Heart Surg Forum. 2014;17(5):E253-7.

10. Waterford SD, Di Eusanio M, Ehrlich MP, Reece TB, Desai ND, Sundt TM, Myrmel T, Gleason TG, Forteza A, de Vincentiis C, DiScipio AW, Montgomery DG, Eagle KA, Isselbacher EM, et al. Postoperative myocardial infarction in acute type A aortic dissection: A report fron the international registory of acute aortic dissection. J Thorac Cardiovasc Surg. 2017;153(3):521-7.

11. Creswell LL, Kouchoukos NT, Cox JL, Rosenbloom M. Coronary artery disease in patients with type a aortic dissection. Ann Thorac Surg. 1995;59:585-90.

12. Rizzo RJ, Aranki SF, Aklog L, Couper GS, Adams DH, Collins JJ, et al. Rapid non-invasive diagnosis and surgical repair of acute ascending aortic dissection: improved survival with less angiography. J Thorac Cardiovasc Surg. 1994:108:567-75.

13. Kojima S, Suwa T, Fujiwara $Y$, Inoue $K$, Mineda $Y$, Ohta $H$, et al. Incidence and severity of coronary artery disease in patients with acute aortic dissection : comparison with abdominal aortic aneurysm and arteriosclerosis obliterans. J Cardiol. 2001:37:165-71.

14. Tamura K, Sugizaki Y, Kumazaki T, Tanaka S. Atherosclerosis-related aortic dissection. Jpn J Thorac Surg. 2000;53:194-201.

15. Christoph AN, Yskert VK, Volkmar N, Volker SAP, Carsten B, Dietmar HK, et al. The diagnosis of thoracic aortic dissection by noninvasive imaging procedures. NEJM. 1993;328:1-9.

16. Mark AC, Daniel WJ, J.Donald E, Jonathan LH, Alan TH, Alan HM et al. Atherosclerotic vascular disease conference : writing group V:medical decision making and therapy. Circulation 2004;109:2634-3642.

17. Tsai T, Trimarchi S, Nienaber CA. Acuteaortic dissection: perspectives from the international registry of acute aortic dissection (IRAD). Eur J Vasc Endvasc Surg. 2009:37:149-59.

18. Pepe LA, Awais M, Woznicki EW, Suzuki T, Trimarchi S, Evangelista A, et al. Presentation, diagnosis, and outcomes of acute aortic dissection. 17-year trends from the international registry of acute aortic dissection. J Am Coll Cardiol. 2015;66:350-8

19. Achneck H, Modi B, Shaw C, Rizzo J, Albomoz G, Fusco D, et al. Ascending thoracic aneurysm are associated with decreased systemic atherosclerosis Chest. 2005;128(3):1580-6.

20. Chau K, Elefteriades JA. Ascending thoracic aortic aneurysm protect against myocardial infarctions. Int J Angiol. 2014;23(3):177-82.

21. Ito S, Akutsu K, Tamori Y, Sakamoto S, Yoshimura T, Hashimoto H, Takeshita S. Differences in atherosclerotic profiles between patients with thoracic and abdominal aortic aneurysm. Am J Cardiol. 2008;101:696-9.

\section{Ready to submit your research? Choose BMC and benefit from:}

- fast, convenient online submission

- thorough peer review by experienced researchers in your field

- rapid publication on acceptance

- support for research data, including large and complex data types

- gold Open Access which fosters wider collaboration and increased citations

- maximum visibility for your research: over $100 \mathrm{M}$ website views per year

At BMC, research is always in progress.

Learn more biomedcentral.com/submissions 